\title{
XXXVI. On the refraction and polarization of heat
}

\author{
James D. Forbes Esq. F.R.SS. L. E.
}

To cite this article: James D. Forbes Esq. F.R.SS. L. E. (1835) XXXVI. On the refraction and polarization of heat, Philosophical Magazine Series 3, 6:33, 205-214, DOI: $10.1080 / 14786443508648571$

To link to this article: http://dx.doi.org/10.1080/14786443508648571

曲 Published online: 01 Jun 2009.

Submit your article to this journal ๘

山 Article views: 2

Q View related articles ¿ 
Prof. Forbes on the Refraction and Polarization of Heat. 205

a sphere of the same mass on an equidistant particle, but $\cos \mu$ is nearly = sine of latitude; hence the attraction along a line which makes with the axis an angle whose $\cos =\frac{1}{\sqrt{3}}$, is the same as that of a sphere of the same mass.

8. When the particle is on the equator of the oblate spheroid $\delta=a$ and $\mu=90^{\circ}$; hence $\mathrm{A}=\frac{4 \pi f b}{3}\left\{1+\frac{3}{10} e^{2}\right\}$, and if $e$ be small $e^{2}=2 \varepsilon$ nearly; hence $\mathbf{A}=\frac{4 \pi f b}{3}\left\{1+\frac{3}{5} \varepsilon\right\}$.

9. If the particle be at the pole of the oblate spheroid $\delta=b$, and neglecting powers of $\_$above the first,

$$
\mathrm{P}=\frac{4 f^{b}}{3}\left\{1+\frac{4}{5} \varepsilon\right\} .
$$

10. Should the ellipsoid become a prolate spheroid round the axis of $a$, the formula becomes

$$
\mathrm{D}=\frac{f \mathrm{M}}{\delta^{2}}\left\{1+\frac{3}{10}\left(\frac{3 \cos ^{2} \lambda-1}{\delta^{2}}\right) a^{2} e^{2}\right\} b \text { being }=c .
$$

If the point be at the pole of the spheroid $\cos \lambda=1$, and $\delta=a$, and the formula $\mathrm{P}^{\prime}=\frac{4 \pi f b}{3}\left\{1+\frac{1}{5} \varepsilon\right\}$.

11. If at the equator $\delta=b$ and $\cos \lambda=0$ and the formula becomes $\mathrm{B}=\frac{4 \pi f b}{3}\left\{1+\frac{2}{5} \varepsilon\right\}$, omitting the powers of $\varepsilon$ above the first.

Trinity College, Dublin, Nov. 12, 1834.

XXXVI. On the Refraction and Polarization of Heat. By James D. Fonbes, Esq., F.R.SS. L.\& E., Professor of Natural Philosophy in the University of Edinburgh.

[Continued from p. 142.]

\section{§ 2. On the Polarization of Heat by Tourmaline.}

18. T $T$ is well known that two slices of tourmaline cut parallel 1 to the axis of the crystal, as they are looked through with their axes parallel or perpendicular to one another, transmit a great portion of the incident light in the one case, and almost wholly intercept it in the other.

19. It occurred to me as a curious question, at an early period of my researches, whether non-luminous heat would un- 


\section{Prof. Forbes on the Refraction and Polarization of Heat.}

dergo any similar change in similar circumstances. I made a preliminary experiment with heat from an oil-lamp (not an Argand), and though, when the axes were crossed, the whole light was stopped, the heat transmitted appeared to be as intense as before. The tourmalines which I employed were mounted on glass, and were kindly lent to me by the Rev. Mr. Craig. Struck with the singularity of the result, I repeated the experiment with additional precautions, and I found that some circumstances prevented this statement from being true in all its generality. The quantity of heat transmitted being very small, the lamp, the tourmalines, and the pile were very near to one another; and, as the tourmaline absorbs heat with great rapidity, I found that a minute difference might exist if the experiment was made first with the axes parallel, and then with the axes crossed, which difference might yet be made up by the secondary radiation from the heated tourmaline, which was constantly becoming more intense. Such at least appeared to be the chief source of error, which I am particular in stating, because I afterwards discovered that M. Melloni had been led to the very same conclusion as I at first was, and had published it.

20. When I proceeded to verify my results by a series of successive observations, under the two conditions of axes parallel and axes crossed, so as to eliminate any error from a constantly progressive change, I perceived my mistake. As this illustrates the method by which almost all my observations have been reduced, I shall give an example. Two measures of intensity in the position where least light was transmitted, which is marked Dark, have their mean taken, which is then compared with the intervening observation in the position of greatest illumination, which is marked Light. These tourmalines we may call $\mathrm{A}$ and $\mathrm{B}$.

1834, Dec. 4.-Oil Lamp* six inches from Centre of the Pile.

\begin{tabular}{|c|c|c|c|c|}
\hline \multirow{5}{*}{$\begin{array}{l}\text { Deviations of } \\
\text { galvanometer. }\end{array}$} & Dark. & Mean. & Light. & Ratio. \\
\hline & $\$$ & 4.5 & $\stackrel{\circ}{5} \cdot 2$ & $86: 100$ \\
\hline & $4 \frac{4}{4}$ & $5 \cdot 0$ & $6 \cdot 0$ & $83: 100$ \\
\hline & & $5 \cdot 2$ & 6.0 & $86: 100$ \\
\hline & & $5 \cdot 4$ & $6 \cdot 5$ & $83: 100$ \\
\hline
\end{tabular}

* The oil lamp used when not expressly called "Argand," was Locatelli's lamp with a solid square wick, which is what M. Melloni employed. 
Another series on a different day gave the following quantities per cent. 91, 8\%, 94. Mean of the whole, 86.4: 100 .

21. Having obtained these decisive results, I proceeded to operate with other sources of heat, and with different tourmalines. Anxious to avoid the interposition of glass, I had a pair of tourmalines of large size cut without any support. But the best kind will not bear this, and they polarized imperfectly. Only fifteen sixteenths (approximately) of the light in the bright position was stopped in the dark, whilst with the tourmalines $A$ and $B$ every vestige of the brightest gas flame was excluded. With these tourmalines (which may be called $\mathbf{C}$ and D) I verified the general conclusions. I was unable to get sufficient effect from non-luminous heat to verify the law in that case.

22. I had two very fine tourmalines cut and mounted on extremely thin glass. These we may call $\mathrm{E}$ and $\mathrm{F}$. With them I was enabled to extend and verify the law of polarization even to the case of non-luminous heated brass, (whose temperature when warmed by alcohol, M. Melloni estimates at $390^{\circ}$ cent. $=734^{\circ}$ Fahr.) And it is worthy of observation that among twenty-nine pairs of comparative observations, made with three sets of tourmalines, and heated from the following sources, Argand lamp, simple oil lamp, platinum rendered incandescent by alcohol, and non-luminous hot brass, there was only one which did not give positive indications of polarization. The effect, however, with non-luminous heat is extremely feeble, and the percentage very small, because it is with great difficulty that we can obtain results at all with the interposition of two plates of glass, and two of tourmaline (however thin), and a large portion of heat which reaches the pile is derived from conduction, and therefore diminishes the proportion of polarization.

23. It is very important to observe, that in this and all similar cases, the effect of conduction or the secondary radiation of heat from screens always tends to disguise, and never to produce the differences of which ree are in search; that is, so long as the means of alternate observations are taken in the way we have described.

24. The following are the general results of my experiments on tourmaline.

Source of Heat. No. of Comparisons. Proportions of Heat polarized by

\begin{tabular}{|c|c|c|c|}
\hline$A$ and $B$ & E and $F$ & Tourmalines $\mathrm{A}$ and $\mathrm{B}$ & Eand $F^{*}$ \\
\hline Argand & 3 & & 167 \\
\hline Oil lamp, .............7 7 & 3 & 14 per cent. & 11 \\
\hline Incandescent platinum, 4 & 3 & 15 & 12 \\
\hline Brass at $700^{\circ}$, & 7 & gative) & 3. \\
\hline
\end{tabular}

* It appears that the axes of $E$ and $F$ were not precisely crossed in these experiments. 
I cannot, therefore, entertain any doubt on the polarization of heat by tourmaline, notwithstanding the opposite result which M. Melloni (and I also at first) obtained.

25. Some very curious considerations arise from the study of these facts. Since 84 per cent. of the heating rays of an Argand lamp pass through the second tourmaline in the case where the light is entirely stopped, we must adopt one of two conclusions: either that the heat which necessarily accompanies light is excessively small, or else that radiant light during its instantaneous passage through a medium, is capable of being converted into radiant heat. The latter supposition we have no analogies strong enough to warrant us to adopt, though were heat really not polarized by tourmaline, we must have done so. All our experiments point to the first, namely, that heat, though intimately partaking of the nature of light, and accompanying it under certain circumstances (as refraction and reflection), is capable of almost complete separation from it in others. Thus, almost all the heat is stopped by a plate of alum, which transmits neariy the whole light, whilst a second plate of tourmaline stops the whole light, but transmits a large share of the heat.

26. The tourmaline affords a precious method of investigating the influence of light, since the quantity of matter to be traversed is exactly the same, whatever be the direction of the axes of the crystal. In this it differs from all other modes of absorption.

27. M. Melloni has proved that the more light that accompanies heat, the greater power it has to traverse most media, such us clear glass or alum. I made several experiments on the quality of the heat which passed through the tourmalines in their darkest and in their brightest positions, and I always found that the presence of the light materially increased the power of the heat to permeate such screens, though we have seen how little it added to the quantity.

28. This fact, namely, that by sifting, as it were, heat separate from light, we give to it the characters of non-luminous heat, or heat of low temperature, and small refrangibility, such as exists beyond the red extremity of the spectrum, seems so far congenial with analogy. But according to Melloni's experiments, this does not hold with other degrees of sifting of heat. Thus the absorption of all rays of light, except the blue, the yellow, or the red, by coloured glasses, does not give the peculiar character to the heat which it possesses, when it accompanies light in the process of refraction, namely, that of permeating screens (in general) more readily as the refrangibility is greater. Hence I conceive we must conclude, that 
heat in the spectrum accompanies the light, and has corresponding properties, but that in general these properties are independent of the nature of the accompanying light.

29. The only fact which appeared to militate against this view, so far as coloured media were concerned, was the case of green light. It appeared probable that this arose from some peculiarity in the absorptive nature of the material, not from its colour. To investigate this point, I tried the relative transparency (or diathermancy, to borrow a word from M. Melloni,) of screens for the heat of various coloured flames. I did not find that marked peculiarity in the green, which M. Melloni observed in the absorptive action of green glass. The following results are not pretended to be numerically accurate, but they are probably nearly comparable. The flames were obtained from alcohol, combined with the following substances: for the red, nitrate of strontia (the muriate is better); the yellow, with muriate of soda; the green, boracic acid; the blue, pure alcohol. The unsteadiness of intensity of an alcohol flame prevents great numerical accuracy.

\begin{tabular}{|c|c|c|c|}
\hline Numbe & er of Ra & leat out & 100 transm \\
\hline Colour of Flame. & Alum. & Glass. & Rock Salt. \\
\hline Red,............ & 11 & 26 & 85 \\
\hline Yellow, ............ & $11 \frac{1}{2}$ & 28 & 87 \\
\hline Green, ................ & 11 & 26 & 84 \\
\hline Blue, ......... & 10 & 30 & 83 \\
\hline
\end{tabular}

The differences are certainly within the limits of errors of observation.

30. I am disposed to believe, however, that in these experiments, as well as Melloni's, some effect is probably due to the simple presence of light of a particular quality, though its heating power may be small. This my experiments with tourmalines countenance. We can hardly, however, look for a solution of these difficulties, until some of the most stubborn difficulties in the theory of light, the laws of dispersion and absorption (and especially that peculiar absorptive power which permits the tourmaline only to transmit one polarized pencil,) are completely overcome. Meanwhile, we pass with pleasure to the consideration of some of those properties of heat which serve to connect it with the best determined and best explained departments of optics.

\section{\$3. On the Polarization of Heat by Refraction and Reflection.}

31. Soon after the discoveries connected with the polarization of light, which illustrated the earlier part of this century, the question of the polarization of heat was taken up by Malus

Third Series. Vol. 6. No.33. March $1835.2 \mathrm{E}$ 


\section{Prof. Forbes on the Refraction and Polarization of Heat.}

and Berard.* In the case of heat accompanying solar light, it was decisively proved, as might have been anticipated; but in the case of heat from terrestrial, and especially non-luminous sources, though M. Berard considered that he had proved it, he gives no quantitative measures which could enable us to judge of the evidence, nor does it appear that subsequent experimenters have been able to verify the assertion. $\uparrow$

32. The importance of the subject will be estimated, when we consider the very definite laws to which the polarization of light is subjected, and the accuracy with which they are represented upon the undulatory hypothesis. If heat, when wholly deprived of light, be subjected to similar modifications, our progress in acquiring a knowledge of the true nature of heat will be greatly advanced by our previous analogical acquaintance with the laws of light. $\neq$

33. I had been led to make the experiment with tourmalines, because of the convenience with which all experiments on transmitted heat are made by means of the multiplier. But at the same time it occurred to me, that the transmitted pencil of heat passing through laminæ at the polarizing angle might likewise be adapted to the instrument. I had previously noticed the large proportion of heat transmitted by thin plates of mica, and I thought of applying bundles of mica-plates placed at the polarizing angle, and so cut from the plate, that

- Mémoires d'Arcueil, tom. iii.

$\uparrow$ See Professor Powell's papers in the Edinburgh Journal of Science, Second Series, vols. vi. and $x$.

$\ddagger$ The importance of analogies In science has not perhaps been suffi. ciently insisted on by writers on the methods of philosophizing. A clear perception of connexion has been by far the most fertile source of discovery. That of gravitation itself was only an extended analogy. The undulatory theory of light has been preeminently indebted to the co-ordinate science of acoustics, which afforded to Dr. Young the most plausible basis of his curious and original investigations; and unless that science had existed, it may be doubted whether such a speculation would ever have been invented, or, if invented, would have been listened to. The penetrating sagacity of M. Fresnel, in his prosecution of the subject, has led him to draw from mechanical and mathematical analogies, accurate representations of laws which no strict reasoning could have enabled him to arrive at. Of this his marvellous prediction of the circular polarization of light by two total reflections in glass, is the most prominent example, a conclusion which no general acuteness could have foreseen, and which was founded on the mere analogy of certain interpretations of inaginary expressions. The mere reasoner about phænomena could never have arrived at the result,-the mere mathematician would have repudiated a deduction founded upon analogy alone. The cause of the long postponement of the discovery of electromagnetism was the complete apparent breach of analsgy between the modes of action of the electric and magnetic forces, and any others previously known. 
the plane of incidence corresponded with one of the neutral sections of the mica-plate, (the section used was that perpendicular to the principal plane,) so that the transmitted pencil would be polarized exactly similarly to that refracted through glass or any singly refracting medium.

34. I prepared two pairs of bundles of plates of mica of this description, the first (which I called $A$ and $B$ ) having a thickness of about one fiftieth of an inch, and was split into about ten plates, whilst the others (C and D) were only half the thickness, and contained but half as many reflecting surfaces. I found that these plates, placed at the proper angle, polarized light very satisfactorily. On applying them to heat, I had the satisfaction of finding that not only was heat from an oil lamp most decisively polarized, but also that from a brass plate warmed by alcohol, but so as to be quite invisible in the dark, having probably a temperature (as before mentioned) of about $700^{\circ}$ Fahr. These experiments were made on the 22 nd of November last, and were afterwards amply confirmed*.

35. It is to this mode of observing that I attribute chiefly the success of my after inquiries. The mode of reflection for polarizing is attended with so much inconvenience where a thermometer is concerned, and especially with the multiplier, as to render the employment of it tedious and incommodious; whereas by having two bundles of mica-plates arranged in square tubes, so that the one fits the extremity of the thermal pile, and the other slips into the first, and by turning it round we get observations with plates, whose planes of incidence for rays passing along the axis of the tube, are inclined $0^{\circ}, 90^{\circ}$, $180^{\circ}$, or $270^{\circ}$ to one another, the direction of the ray is generally in a single straight line, and the observations are made in the same manner, and with equal facility as in ordinary experiments on transmission. I have little doubt that in this way the polarization of heat might be proved without the aid of the thermo-multiplier. The plates were fixed at the polarizing angle for light. After what has been said, art. (16), on the refrangibility of heat, it is clear, that the alteration of the polarizing angle, in order to accommodate it to heat, could hardly amount (by Sir David Brewster's law) to a sensible quantity.

* I did not see M. Melloni's second paper till the 10th of December, after I had obtained the chief fundamental results contained in this paper. It does not appear, however, that M. Melloni had thought of applying his instrument to any question of polarization except that of tourmaline, and in a note he alludes to the objections which had been urged against Berard's conclusions, objections which he does not consider to have been overcome. -Ann. de Chimie, lv. 374. 


\section{Prof. Forbes on the Refraction and Polarization of Heat.}

36. I fitted up two other bundles of mica-plates, in square pasteboard tubes of the kind described, which were marked $E$ and $F$, the other plates being occasionally substituted, in order to verify the results, and to show that no accidental peculiarity of the plates could account for the differences observed. My experiments were usually made thus. The tube $\mathrm{E}$ was fixed to the pile; the tube $\mathrm{F}$, containing the other plate, had an index, which pointed to $0^{\circ}$ when the two plates were parallel, to $90^{\circ}$ when they were at right angles, \&c. Five observations were taken; at $0^{\circ}, 90^{\circ}, 180^{\circ}, 270^{\circ}$, and again at $0^{\circ}$. The mean of the first and last were taken; then the mean of this, and the indication at $180^{\circ}$, and the difference between this and the mean at $90^{\circ}$ and $270^{\circ}$, was considered as the polarizing effect. An example will best illustrate this :-

1834, Nov. 26.-Brass heated by Alcohol: $5 \frac{1}{2}$ inches from centre of Pile.

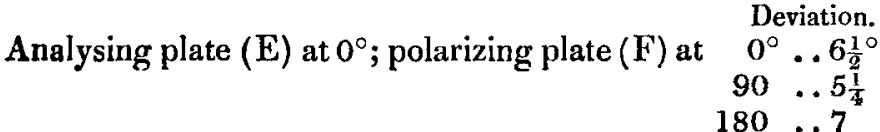

$$
\begin{aligned}
& 270 \ldots 6 \\
& \text { Mean at } 0^{\circ} \ldots 6^{\circ} \cdot 9 \\
& 0^{\circ} \ldots 7 \frac{1}{4} \\
& 180^{\circ} \ldots 7^{\circ} 0 \\
& \text { Mean, ...6 6.9 Ratio } 100: 81 \text {, or } 19 \text { per cent. } \\
& \text { Mean at } \left.90^{\circ} \text { and } 270^{\circ}, \ldots 5 \cdot 6\right\} \text { polarized. }
\end{aligned}
$$

The general concordance of these experiments will be gathered from the following list of results.

37. With non-luminous heat from brass about $700^{\circ}$; ratio of effect, when plates $\mathrm{E}$ and $\mathrm{F}$ were parallel and crossed, $100: 78 ; 100: 76 ; 100: 80 * ; 100: 81$ (from five observations each), with plates $\mathrm{E}$ and $\mathrm{A}$ (from three observations each), $100: 74 ; 100: 59 ; 100: 68 ; 100: 60$; with $A$ and $B$, ratios $100: 78 ; 100: 72$.

38. With non-luminous heat from mercury, about $500^{\circ}$, plates $E$ and $F ; 100: 77 ; 100: 90$, plates $E$ and $A ; 100: 88$; with $A$ and $B, 100: 78$.

39. But even with heat from water below the boiling-point, I was able, by the improved method of observing the galvanometer, art. (5), (6), to establish completely the polarizing effect. One series of six comparisons (conducted as in (20), )

* Plate B was used to polarize in this experiment. 
gave for the proportions of heat transmitted, when the plates $\mathbf{E}$ and $\mathrm{F}$ were parallel and crossed, 100:93; another of eight comparisons, gave 100:96; a third, of eight, 100:92. Among these twenty-two comparisons, only one gave a result slightly negative.

40. With platinum rendered incandescent by alcohol, the effect appears decidedly greater than with any other source of heat $\mathrm{I}$ have tried. Plates $\mathrm{E}$ and $\mathrm{F}$; ratios of effect when $p a-$ rallel and crossed, $100: 59 ; 100: 62 ; 100: 66 ; 100: 54$. The brilliancy of the incandescence affects materially the transmission.

41. Alcohol flame, as might be anticipated, is less steady; means from sets of five observations, with plates $\mathrm{E}$ and $\tilde{\mathrm{F}}$; $100: 66 ; 100: 72 ; 100: 79 ; 100: 42 ; 100: 62$.

42. With the simple oil-lamp of Locatelli; plates E and F, the ratios are $100: 76 ; 100: 73.5 ; 100: 79$.

43. With Argand lamp, and glass chimney; plates $\mathrm{E}$ and F; ratios, $100: 70 ; 100: 72$; results very steady.

4.4. When we combine these results*, and compare them with the quantity of light polarized, which was derived from some rude photometrical experiments, which agreed pretty nearly, we get the following approximations to the degrees of polarization, by a given combination, and depending on the source of heat.

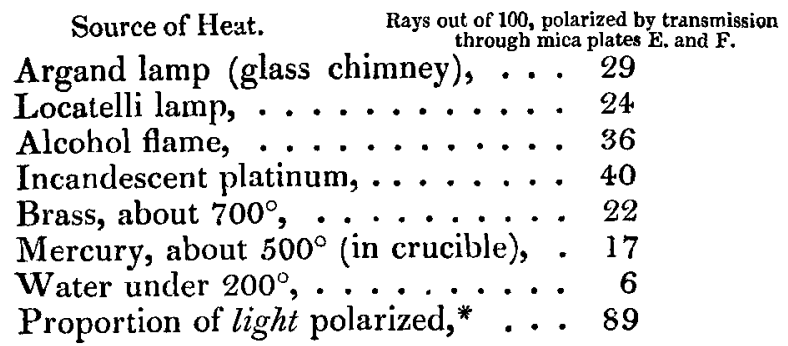

45. So completely and satisfäctorily made out does the polarization of heat appear by these concurrent experiments, that it was little more than a matter of curiosity to verify it in the

* It should be remarked, that these experiments contain all the measures I have made with a view to this determination, except two, which were made the very first day I discovered the fact, and which were not accurate enough to be employed. I mention this, because, in such experiments, it is important to be assured of the constancy and marked nature of a result, which can only be appreciated by keeping back no fairly marle observation.

+ Though I am not aware of any source of error, I cannot help thinking. that, in this case, and in that of the tourmaline, art. (21.), the defalcation of light is estimated too high. 
case of reflection from surfaces, as well as in that of transmission through plates. This, however, I also established, though not without much more trouble than the other, the change of direction of the ray by reflection presenting a troublesome necessity for making the thermometric instrument, that is, the pile, moveable; at least, this was the most unexceptionable method. I fully established the fact of comparative nonreflection from a second reflecting plate of mica, the plane of incidence being at right angles to the first; but I had more reason than ever to be satisfied of the value of the simple and effective method of transmission through thin mica-plates. In fact, it was only by the aid of that method that I could have advanced to the still more delicate inquiries which, by the constancy of my first results, I was encouraged to undertake.

[To be continued.]

\section{Revieros, and Notices respecting New Boals.}

The Chemical Catechism, Thirteenth Edition. By the late Sameed Parkes, F.L.S., G.S., W.S., M.R.I., \&c. Revised, and adapted to the present state of Chemical Science, by E. W. Brayley, Jun., A.L.S., of the London Institution. London, 1834. 8vo. pp. xl. and 681: with a frontispiece and two other plates.

$\mathrm{H}^{\mathrm{EW}}$ elementary works on any branch of science, we believe, have attained a popularity so great or so enduring, as the Chemical Catechism of the late Mr. Parkes. Coeval, in its original publication, with the first great analytical discoveries of Davy, it supplied the public demand for knowledge respecting the phænomena and objects of Chemistry, which those discoveries had either mainly excited, or if they did not actually excite, had immensely promoted and increased. As the science progressed, displaying fresh wonders to attract the lover of novelty and deeper truths to interest the philosophical student, as well as more and still more important applications to the arts of life, new editions of the Chemical Catechism were prepared by the author to meet the still increasing demand; into which he introduced, from time to time, as they were elicited, the new facts of Chemical discovery. Between the first appearance of the work in the year 1806 and the publication of the edition now before us-a space of about twentyseven years-nearly a thousand copies, upon an average, as we gather from one of the "Advertisements," were disposed of every year.Ample reasons these for the publication of a new edition, adapted to the existing state of Chemical knowledge.

The plan of this work is too well known to the public to require particular explanation : suffice it to say that the body of it consists of a popular elementary view of Chemical Science, delivered in the catechetical form, to which are attached numerous illustrative notes, giv- 